\title{
Galectin-3 levels relate in children to total body fat, abdominal fat, body fat distribution, and cardiac size
}

\author{
Magnus Dencker $^{1}$ (D) Daniel Arvidsson ${ }^{1,2} \cdot$ Magnus K. Karlsson $^{3} \cdot$ Per Wollmer $^{1} \cdot$ Lars B. Andersen $^{4,5} \cdot$ Ola Thorsson $^{1}$
}

Received: 25 January 2017 / Revised: 20 December 2017 / Accepted: 21 December 2017 / Published online: 11 January 2018

(C) The Author(s) 2018. This article is an open access publication

\begin{abstract}
Galectin-3 has recently been proposed as a novel biomarker for cardiovascular disease in adults. The purpose of this investigation was to assess relationships between galectin-3 levels and total body fat, abdominal fat, body fat distribution, aerobic fitness, blood pressure, left ventricular mass, left atrial size, and increase in body fat over a 2-year period in a population-based sample of children. Our study included 170 children aged 8-11 years. Total fat mass and abdominal fat were measured by dual-energy $\mathrm{x}$-ray absorptiometry (DXA). Body fat distribution was expressed as abdominal fat/total fat mass. Maximal oxygen uptake was assessed by indirect calorimetry during a maximal exercise test and scaled to body mass. Systolic and diastolic blood pressure and pulse pressure were measured. Left atrial size, left ventricular mass, and relative wall thickness were measured by echocardiography. Frozen serum samples were analyzed for galectin-3 by the Proximity Extension Assay technique. A follow-up DXA scan was performed in 152 children 2 years after the baseline exam. Partial correlations, with adjustment for sex and age, between galectin-3 versus body fat measurements indicated weak to moderate relationships. Moreover, left atrial size, left ventricular mass, and relative wall thickness and pulse pressure were also correlated with galectin-3. Neither systolic blood pressure nor maximal oxygen uptake was correlated with galectin-3. There was also a correlation between galectin-3 and increase in total body fat over 2 years, while no such correlations were found for the other fat measurements.

Conclusion: More body fat and abdominal fat, more abdominal body fat distribution, more left ventricular mass, and increased left atrial size were all associated with higher levels of galectin-3. Increase in total body fat over 2 years was also associated with higher levels of galectin-3.
\end{abstract}

Communicated by Mario Bianchetti

Magnus Dencker

magnus.dencker@skane.se

Daniel Arvidsson

daniel.arvidsson@med.lu.se

Magnus K. Karlsson

Magnus.Karlsson@med.lu.se

Per Wollmer

per.wollmer@med.lu.se

Lars B. Andersen

Lars.Bo.Andersen@hisf.no

Ola Thorsson

ola.thorsson@med.lu.se
1 Department of Medical Imaging and Physiology, Skåne University Hospital, Lund University, 20502 Malmö, Sweden

2 Center for Health and Performance, Department of Food and Nutrition, and Sports Science, University of Gothenburg, Gothenburg, Sweden

3 Department of Clinical Sciences and Orthopaedics, Clinical and Molecular Osteoporosis Research Unit, Skåne University Hospital, Lund University, Lund, Sweden

4 Department of Teacher Education and Sport, Sogn and Fjordane University College, Sogndal, Norway

5 Department of Sports Medicine, Norwegian School of Sport Sciences, Oslo, Norway 


\section{What is Known:}

- Galectin-3 has been linked to obesity and been proposed to be a novel biomarker for cardiovascular disease in adults.

- Information on this subject in children is very scarce.

What is New:

- The present study demonstrates a relationship between galectin-3 levels and total body fat, abdominal fat, body fat distribution, cardiac size and geometry, and increase in total body fat over 2 years in young children.

Keywords DXA · Body fat · Children · Galectin-3

\begin{tabular}{ll}
\multicolumn{2}{l}{ Abbreviations } \\
AU & Arbitrary units \\
DXA & Dual-energy x-ray absorptiometry \\
IVS & End-diastolic inter-ventricular septum thickness \\
LVDD & End-diastolic left ventricular diameter \\
PW & End-diastolic posterior wall thickness
\end{tabular}

\section{Introduction}

Galectin-3 is a protein that has been suggested to stimulate collagen production and hypertrophy as responses to injury through different mechanisms [1]. It has also emerged as a novel molecule for regulatory functions within the immune system $[2,3]$. The potential role of galectin-3 as a circulating biomarker for cardiovascular diseases has been mainly tested in patients with heart failure [1, 4-6]. Galectin-3 levels have been shown to correlate with clinical outcomes in patients with atherothrombosis [7], and to correlate with traditional risk factors for cardiovascular diseases and with mortality in subjects from the general population [8]. Elevated galectin-3 levels have also been associated with increased risk for stroke after carotid endarterectomy [9]. In adults, galectin-3 has been shown to be elevated in obesity $[10,11]$. As obese children and adolescents have an increased risk of developing adult obesity and are more likely to experience significant shortand long-term health problems [12-14], it is relevant to explore potential relationships between galectin-3 versus body fat and other markers for health at a young age. There are scarce data on this subject in children [15]. The purpose of this investigation was therefore to assess relationships between galectin-3 levels and total body fat, abdominal fat, body fat distribution, aerobic fitness, blood pressure, left ventricular mass, left atrial size, and also increase in body fat over 2 years in a community sample of children.

\section{Material and methods}

\section{Subjects}

Children were recruited from four different schools in Malmö, Sweden. The schools were all situated in socially homogeneous middle-class areas with inhabitants of essentially non-immigrant origin. All 477 children (boys $=259$, girls $=$ 218) attending third or fourth grade were invited to participate. Out of these, 248 accepted the invitation (boys $=140$, girls $=$ 108), and parents of 172 children gave consent to give blood sample. A complete data set with blood samples and other measures were available in 170 children ( 92 boys and 78 girls) giving an inclusion frequency of $36 \%$. A 2-year follow-up DXA scan was available in 152 children ( 84 boys and 68 girls). A separate study of anthropometric data, from school nurses, for all children that received an invitation to participate in the study showed no significant differences in height, body mass, or BMI between the children that chose to participate and those who did not [16].

\section{Anthropometric measures}

Anthropometric measures were performed at baseline and at the follow-up measurement $(2.0 \pm 0.1)$ years later. Height was measured to the nearest $1 \mathrm{~cm}$ using a fixed stadiometer (Hultafors AB, Hultafors, Sweden) and body mass was measured to the nearest $1 \mathrm{~kg}$ (Avery Berkel model HL 120, Avery Weigh-Tronix Inc., Fairmont, MN, USA). Puberty status was assessed by self-evaluation according to Tanner [17].

\section{Dual-energy x-ray absorptiometry}

Body composition was measured by DXA total body scan (DPX-L version 1.3z, Lunar, Madison, WI, USA), both at baseline and at the follow-up measurement. Total body fat mass and abdominal fat were quantified. Percent body fat was calculated as percentage of total body mass. Body fat distribution was calculated as abdominal fat/total body fat mass. Studies have shown that DXA provides accurate measurements of fat mass, including regional fat mass [18].

\section{Measurement of aerobic fitness}

Maximal oxygen uptake was determined by a maximum exercise test at the baseline. The test was performed on a bicycle ergometer (Rodby rhc, model RE 990, Rodby Innovation AB, Karlskoga, Sweden). Expired gas was analyzed for the 
concentration of $\mathrm{O}_{2}$ and $\mathrm{CO}_{2}$ (Sensor Medics 2900, SensorMedics Inc., Yorba Linda, CA, USA). All children used the same protocol with an initial workload of $30 \mathrm{~W}$ and an increase of $15 \mathrm{~W}$ per minute. Maximum heart rate and maximum respiratory exchange ratio were recorded. Maximal oxygen uptake was determined as the highest value during the last minute of exercise and scaled to body mass $(\mathrm{ml} / \mathrm{min} / \mathrm{kg}$ ). The exercise test was considered acceptable if it met one of the following criteria: maximum respiratory exchange ratio $\geq 1.0$, maximum heart rate $>90 \%$ of predicted value, or signs of intense effort [19].

\section{Blood pressure}

A Dinamap pediatric vital sign monitor (model XL, Critikron Inc., Tampa, FL, USA) was used to measure systolic and diastolic blood pressure in the seated position after $15 \mathrm{~min}$ rest [20]. The mean of three measurements was used. Pulse pressure was calculated as the difference between systolic and diastolic blood pressure.

\section{Echocardiography}

Echocardiographic examination was performed using Sonos 2500 (Philips Inc., Eindhoven, the Netherlands) or Aspen (Acuson Inc., Mountain View, CA, USA) and in accordance with the American Society of Echocardiography recommendations [21]. The following variables were measured: enddiastolic left ventricular diameter (LVDD), left atrial endsystolic diameter, end-diastolic inter-ventricular septum thickness (IVS), and end-diastolic posterior wall thickness (PW). Left ventricular mass was calculated using the American Society of Echocardiography convention: left ventricular mass $=0.83 \times\left[(\mathrm{LVDD}+\mathrm{IVS}+\mathrm{PW})^{3}-\mathrm{LVDD}^{3}\right]+$ 0.6 (measurements in $\mathrm{cm}$ ) [21]. Both left ventricular mass and left atrial size were indexed for height [22-24]. Relative wall thickness of the left ventricle was calculated as $2 \times \mathrm{PW} / \mathrm{LVDD}$ [21].

\section{Blood samples}

Non-fasting venous serum samples were drawn from 172 children and stored at $-70{ }^{\circ} \mathrm{C}$ until analysis. The samples were collected in conjunction with the DXA measurement. Galectin-3 was analyzed by the Proximity Extension Assay technique using the Proseek Multiplex CVD $96 \times 96$ reagents kit (Olink Bioscience, Uppsala, Sweden) at the Clinical Biomarkers Facility, Science for Life Laboratory, Uppsala, as previously described $[25,26]$. The intra- and inter-assay variations were 9 and $12 \%$, respectively. Data are presented as arbitrary units (AU). Values can be transformed to actual concentrations on the Olink Bioscience website. Two samples were excluded due to technical problems at the analysis.

\section{Statistical analyses}

All analyses were made in Statistica 12 (StatSoft Inc., Tulsa, OK, USA). The descriptive data are presented as means \pm SD. Differences in anthropometric data between boys and girls were tested using Student's $t$ test. Distributions of body fat measurements and abdominal fat were skewed and therefore normalized by natural logarithm. Regression analysis was used to calculate partial correlations for all children, with adjustment for sex and age, between the galectin-3 and total body fat, abdominal fat, percent body fat, body fat distribution, maximal oxygen uptake, systolic and diastolic blood pressure, pulse pressure, left ventricular mass, and left atrial size. Partial correlations were also calculated between biomarkers and change in total body fat, abdominal fat, percent body fat, and body fat distribution over the 2-year follow-up period, adjusted for sex, age, and change in Tanner stage. A value of $P<0.05$ was regarded as statistically significant.

\section{Results}

Children that did not consent to give a blood sample were slightly younger than those who gave consent $(9.6 \pm 0.6 \mathrm{vs}$. $9.9 \pm 0.6$ years, $P=0.002$ ). No differences were found in anthropometric, fitness, or DXA data between those children who were part of the final study group at baseline and those who were not (data not shown). The children who did not participate in the follow-up were slightly younger at baseline than those who did $(9.7 \pm 0.6$ vs. $9.9 \pm 0.6$ years, $P=0.005)$. There were no differences in anthropometrics, fitness, or DXA data between those who participated in the follow-up and those who did not (data not shown). At baseline, three girls were Tanner stage 2; all other children were Tanner stage 1. The distributions of Tanner score at follow-up were ( $\mathrm{N}$ for stage $1=18$, stage $2=63$, stage $3=49$, stage $4=22$ ). Galectin-3 was borderline significantly related to change in Tanner stage $(r=-0.15, P=0.064)$, and partial correlations for the follow-up measurements were adjusted for change in Tanner stage. At baseline, girls had more total body fat and abdominal fat, higher percent body fat, lower maximal oxygen uptake, and less left ventricular mass than boys. At follow-up, boys had a higher increase in percent body fat. Girls had higher Tanner score than boys at follow-up. Summary of baseline and follow-up data is displayed in Table 1. Galectin-3 was associated with age $(r=-0.17, P<0.05)$ and partial correlations were therefore adjusted for age. Regression analysis indicated weak to moderate relations between galectin- 3 and total body fat, abdominal fat, percent body fat, body fat distribution, left ventricular mass, left atrial size, relative wall thickness, diastolic blood pressure, and pulse pressure. No such correlation was found for systolic blood pressure and maximal oxygen uptake (Table 2). Weak correlation existed 
Table 1 Display of age, anthropometric, fitness, and Tanner statistics $( \pm \mathrm{SD})$ for baseline and follow-up measurements. Galectin-3 in arbitrary units (AU)

\begin{tabular}{|c|c|c|c|}
\hline Variable & Boys $(n=92)$ & Girls $(n=78)$ & $P$ value \\
\hline \multicolumn{4}{|l|}{ Baseline } \\
\hline Age (year) & $10.0 \pm 0.6$ & $9.8 \pm 0.6$ & 0.03 \\
\hline Height $(\mathrm{cm})$ & $141 \pm 7$ & $141 \pm 7$ & 0.69 \\
\hline Body mass (kg) & $35.2 \pm 7.4$ & $34.6 \pm 6.6$ & 0.57 \\
\hline BMI $\left(\mathrm{kg} / \mathrm{m}^{2}\right)$ & $17.5 \pm 2.6$ & $17.4 \pm 2.7$ & 0.90 \\
\hline Total body fat (kg) & $6.2 \pm 4.6$ & $8.0 \pm 4.6$ & 0.01 \\
\hline Percent body fat (\%) & $16.1 \pm 8.3$ & $22.0 \pm 8.5$ & $<0.001$ \\
\hline Abdominal fat (kg) & $2.3 \pm 2.0$ & $3.2 \pm 2.2$ & 0.01 \\
\hline Fat distribution (abdominal fat/total body fat) & $0.36 \pm 0.04$ & $0.37 \pm 0.05$ & 0.09 \\
\hline Fitness $(\mathrm{ml} / \mathrm{min} / \mathrm{kg})$ & $42 \pm 7$ & $36 \pm 6$ & $<0.001$ \\
\hline Maximum heart rate (beats/min) & $189 \pm 14$ & $184 \pm 16$ & 0.03 \\
\hline Respiratory exchange ratio & $1.0 \pm 0.1$ & $1.0 \pm 0.1$ & 0.64 \\
\hline Systolic blood pressure (mmHg) & $104 \pm 8$ & $104 \pm 9$ & 0.75 \\
\hline Diastolic blood pressure (mmHg) & $60 \pm 5$ & $60 \pm 6$ & 0.48 \\
\hline Pulse pressure (mmHg) & $44 \pm 8$ & $43 \pm 7$ & 0.29 \\
\hline Left ventricular mass (g/m) & $53.9 \pm 12.0$ & $48.3 \pm 11.3$ & 0.002 \\
\hline Left atrial diameter $(\mathrm{mm} / \mathrm{m})$ & $19.9 \pm 2.4$ & $19.5 \pm 2.0$ & 0.22 \\
\hline Galectin-3 (AU) & $4.34 \pm 0.31$ & $4.44 \pm 0.55$ & 0.12 \\
\hline Tanner stage score & $1.0 \pm 0.0$ & $1.0 \pm 0.2$ & 0.06 \\
\hline Follow-up & Boys $(n=84)$ & Girls $(n=68)$ & \\
\hline Age (year) & $11.9 \pm 0.6$ & $11.8 \pm 0.6$ & 0.16 \\
\hline Height (cm) & $152 \pm 8$ & $153 \pm 8$ & 0.31 \\
\hline Body mass (kg) & $43.2 \pm 8.6$ & $43.9 \pm 9.1$ & 0.62 \\
\hline BMI $\left(\mathrm{kg} / \mathrm{m}^{2}\right)$ & $18.5 \pm 2.8$ & $18.6 \pm 3.2$ & 0.97 \\
\hline Increase in total body fat (kg) & $2.1 \pm 2.6$ & $2.2 \pm 2.4$ & 0.95 \\
\hline Increase in abdominal fat $(\mathrm{kg})$ & $1.0 \pm 1.2$ & $1.1 \pm 1.5$ & 0.48 \\
\hline Increase in percent body fat $(\%)$ & $1.4 \pm 4.0$ & $0.0 \pm 3.8$ & 0.03 \\
\hline Change in fat distribution & $0.02 \pm 0.03$ & $0.03 \pm 0.15$ & 0.32 \\
\hline Tanner stage score & $2.3 \pm 0.9$ & $2.7 \pm 0.8$ & 0.007 \\
\hline
\end{tabular}

between galectin-3 and increase in total body fat over 2 years but not with increase in abdominal fat, percent body fat, or change in fat distribution (Table 2).

\section{Discussion}

The present study is the first to demonstrate weak to moderately strong associations between galectin-3 levels and total body fat, abdominal fat, body fat distribution, cardiac size and geometry, and increase in total body fat in a population-based sample of young children. These findings may suggest a role of galectin-3 in cardiovascular risk factor stratification in children, which has not been established previously.

The role of galectin- 3 has mainly been investigated in adult patients with heart failure [1, 4-6]. In children, galectin-3 has previously been investigated as an inflammatory marker in chronic hepatitis B infection [27], juvenile idiopathic arthritis [28], or brain neoplasms [29]. We are aware of only one investigation in unselected children that has explored potential relations with galectin-3 and risk factors for diseases [15]. Meeusen and co-workers studied 240 children aged 217 years. No sex differences in galectin-3 levels were found, which agrees with our finding. However, this study found no relationship between galectin-3 levels and BMI, which is in disagreement with our findings of consistent relationships between galectin-3 levels and all the body fat measurements. One could only speculate of reasons for these discrepancies, but with participants from age 2-17 years, a significant amount of noise may be introduced with puberty. It is also known that BMI cannot differentiate between muscle and fat mass. There has been significant debate of the connection between obesity and systemic inflammation [30-33]. In adults, galectin-3 has been shown to be elevated in obesity $[10,11]$, and we confirm a relation to body fat measurements in an unselected population of children. The exact mechanisms behind our findings are not known. Galectin-3 has a variety of regulatory functions within the immune system [2, 
Table 2 Partial correlations and $P$ values, adjusted for sex and age for baseline measurements, between galectin-3 versus different baseline measurements and change in body fat measurements at follow-up, adjusted for sex, age, and change in Tanner score

\begin{tabular}{ll}
\hline Variable & $n=170$ \\
\hline Baseline & \\
Height & $0.11(0.12)$ \\
Body mass & $* 0.28(<0.001)$ \\
BMI & $* 0.29(<0.001)$ \\
Total body fat & $* 0.31(<0.001)$ \\
Percent body fat & $* 0.30(<0.001)$ \\
Abdominal fat & $* 0.30(<0.001)$ \\
Body fat distribution & $* 0.20(0.01)$ \\
Fitness & $-0.11(0.15)$ \\
Systolic blood pressure & $0.03(0.69)$ \\
Diastolic blood pressure & $*-0.16(0.03)$ \\
Pulse pressure & $* 0.16(0.04)$ \\
Left ventricular mass & $* 0.31(<0.001)$ \\
Left atrial diameter & $* 0.17(0.03)$ \\
Relative wall thickness & $* 0.18(0.02)$ \\
Follow-up & $n=152$ \\
Increase in TBF & $* 0.16(0.04)$ \\
Increase in AFM & $0.14(0.09)$ \\
Increase in percent body fat & $0.01(0.88)$ \\
Change in body fat distribution & $-0.01(0.87)$ \\
\hline
\end{tabular}

*Highlights significant $(P<0.05)$ correlations

3] and is known to be produced by adipose tissue and involved in adipose tissue growth and maturation [34, 35]. Moreover, galectin-3 levels are higher in subjects with type 2 diabetes and have been suggested to have a role from prediabetes to type 2 diabetes [11, 36]. The proposed pathways include galectin-3 participation in the adipocytes ability to respond with enlargement to fat overload after a high-fat diet [36].

Based on studies in heart failure patients [1, 4-6], galectin3 was recently recommended as an additive for risk stratification in heart failure patients [37]. Galectin-3 has been shown to stimulate cardiac collagen production and hypertrophy as through a number of different mechanisms [1]. Our finding of relationships between galectin-3 and left ventricular mass, left atrial size, and relative wall thickness is interesting and novel. There was only a modest relationship between pulse pressure and galectin-3, which could suggest that the observed correlations between galectin-3 and cardiac size and geometry are in part mediated by blood pressure. The finding that diastolic blood pressure was associated in an opposite direction than hypothesized could be a random finding. There was no significant relation between galectin-3 and fitness, although the relation was in the hypothesized direction. This could be a stochastic finding and a larger study with more statistical power may give a more definitive answer.
Major strengths of the present investigation are the urban community-based sample, the multitude of measurements, and objective measurement of body fat by DXA. The inclusion frequency in this study of $52 \%$ might be considered somewhat low. A complete data set was available in no more than $36 \%$ (170 out of 477 invited children). However, a separate study of anthropometric data from all children that received an invitation to participate in the study showed no significant differences in height, body mass, or BMI between the children that chose to participate and those who did not [16]. Moreover, there were no major differences (except a slight age difference) in baseline measurements between those who participated in the follow-up versus those who did not. This suggests that the final study group was fairly representative. The fact that we had non-fasting blood samples has not biased the analysis as it has been shown that galectin- 3 levels are not altered by food intake [38].

\section{Conclusions}

The present study establishes a weak to moderate relationship between galectin-3 levels and total body fat, abdominal fat, body fat distribution, cardiac size and geometry, and increase in total body fat over 2 years in unselected young children.

Authors' contributions MD performed statistical analysis, interpretation of data, and writing the first draft of the manuscript. All authors participated in data collection except DA. All authors participated in the design of the study, contributed intellectually to the manuscript, have read the manuscript, and approved the submission.

Funding information Financial support for this study was received from the Swedish Heart-Lung Foundation, the Gyllenstierna Krapperup's Foundation, Lund University, Skåne University Hospital, and Region Skåne.

Compliance with ethical standards The research ethics committee at Lund University, Sweden, approved the study (LU 243-01). All procedures were in accordance with the ethical standards of the institutional and/or national research committee and with the 1964 Helsinki declaration and its later amendments or comparable ethical standards. Written informed consent was obtained from the parents or legal guardian of all participating children.

Conflict of interest The authors declare that they have no conflicts of interest.

Open Access This article is distributed under the terms of the Creative Commons Attribution 4.0 International License (http:// creativecommons.org/licenses/by/4.0/), which permits unrestricted use, distribution, and reproduction in any medium, provided you give appropriate credit to the original author(s) and the source, provide a link to the Creative Commons license, and indicate if changes were made. 


\section{References}

1. Vasile VC, Jaffe AS (2014) Emerging biomarkers for acute heart conditions. Curr Opin Cardiol 29(4):312-318. https://doi.org/10. 1097/HCO.0000000000000077

2. Dhirapong A, Lleo A, Leung P, Gershwin ME, Liu FT (2009) The immunological potential of galectin-1 and -3 . Autoimmun Rev 8(5):360-363. https://doi.org/10.1016/j.autrev.2008.11.009

3. Liu FT, Rabinovich GA (2010) Galectins: regulators of acute and chronic inflammation. Ann N Y Acad Sci 1183(1):158-182. https:// doi.org/10.1111/j.1749-6632.2009.05131.x

4. de Boer RA, Yu L, van Veldhuisen DJ (2010) Galectin-3 in cardiac remodeling and heart failure. Curr Heart Fail Rep 7(1):1-8. https:// doi.org/10.1007/s11897-010-0004-x

5. AbouEzzeddine OF, Haines P, Stevens S, Nativi-Nicolau J, Felker GM, Borlaug BA, Chen HH, Tracy RP, Braunwald E, Redfield MM (2015) Galectin-3 in heart failure with preserved ejection fraction. A RELAX trial substudy (phosphodiesterase-5 inhibition to improve clinical status and exercise capacity in diastolic heart failure). JACC Heart Fail 3(3):245-252. https://doi.org/10.1016/j.jchf.2014. 10.009

6. Meijers WC, de Boer RA, van Veldhuisen DJ, Jaarsma T, Hillege HL, Maisel AS, Di Somma S, Voors AA, Peacock WF (2015) Biomarkers and low risk in heart failure. Data from $\mathrm{COACH}$ and TRIUMPH. Eur J Heart Fail 17(12):1271-1282. https://doi.org/10. 1002/ejhf.407

7. Madrigal-Matute J, Lindholt JS, Fernandez-Garcia CE, BenitoMartin A, Burillo E, Zalba G, Beloqui O, Llamas-Granda P, Ortiz A, Egido J, Blanco-Colio LM, Martin-Ventura JL (2014) Galectin3 , a biomarker linking oxidative stress and inflammation with the clinical outcomes of patients with atherothrombosis. J Am Heart Assoc 3(4):e000785. https://doi.org/10.1161/JAHA.114.000785

8. de Boer RA, van Veldhuisen DJ, Gansevoort RT, Muller Kobold AC, van Gilst WH, Hillege HL, Bakker SJ, van der Harst P (2012) The fibrosis marker galectin- 3 and outcome in the general population. J Intern Med 272(1):55-64. https://doi.org/10.1111/j.13652796.2011.02476.x

9. Edsfeldt A, Bengtsson E, Asciutto G, Dunér P, Björkbacka H, Fredrikson GN, Nilsson J, Goncalves I (2016) High plasma levels of galectin-3 are associated with increased risk for stroke after carotid endarterectomy. Cerebrovasc Dis 41(3-4):199-203. https:// doi.org/10.1159/000443022

10. Pang J, Nguyen VT, Rhodes DH, Sullivan ME, Braunschweig C, Fantuzzi G (2016) Relationship of galectin-3 with obesity, IL-6, and CRP in women. J Endocrinol Investig 39(12):1435-1443. https:// doi.org/10.1007/s40618-016-0515-8

11. Weigert J, Neumeier M, Wanninger J, Bauer S, Farkas S, Scherer MN, Schnitzbauer A, Schäffler A, Aslanidis C, Schölmerich J, Buechler C (2010) Serum galectin-3 is elevated in obesity and negatively correlates with glycosylated hemoglobin in type 2 diabetes. J Clin Endocrinol Metab 95(3):1404-1411. https://doi.org/10.1210/ jc.2009-1619

12. Alberdi G, McNamara AE, Lindsay KL, Scully HA, Horan MH, Gibney ER, McAuliffe FM (2016) The association between childcare and risk of childhood overweight and obesity in children aged 5 years and under: a systematic review. Eur J Pediatr 175(10): 1277-1294. https://doi.org/10.1007/s00431-016-2768-9

13. Gibson LY, Allen KL, Davis E, Blair E, Zubrick SR, Byrne SM (2017) The psychosocial burden of childhood overweight and obesity: evidence for persisting difficulties in boys and girls. Eur $\mathrm{J}$ Pediatr 176(7):925-933. https://doi.org/10.1007/s00431-0172931-y

14. Saner C, Simonetti GD, Wühl E, Mullis PE, Janner M (2016) Circadian and ultradian cardiovascular rhythmicity in obese children. Eur J Pediatr 175(8):1031-1038. https://doi.org/10.1007/ s00431-016-2736-4

15. Meeusen JW, Johnson JN, Gray A, Wendt P, Jefferies JL, Jaffe AS, Donato LJ, Saenger AK (2015) Soluble ST2 and galectin-3 in pediatric patients without heart failure. Clin Biochem 48(18):13371340. https://doi.org/10.1016/j.clinbiochem.2015.08.007

16. Dencker M, Thorsson O, Karlsson MK, Lindén C, Eiberg S, Wollmer P, Andersen LB (2006) Daily physical activity related to body fat in children aged 8-11 years. J Pediatr 149(1):38-42. https://doi.org/10.1016/j.jpeds.2006.02.002

17. Duke PM, Litt IF, Gross RT (1980) Adolescents' self-assessment of sexual maturation. Pediatrics 66(6):918-920

18. Helba M, Binkovitz LA (2009) Pediatric body composition analysis with dual-energy X-ray absorptiometry. Pediatr Radiol 39(7):647656. https://doi.org/10.1007/s00247-009-1247-0

19. Armstrong N, van Mechelen W (eds) (2000) Paediatric exercise science and medicine. Oxford University Press, Oxford

20. Andersen LB, Harro M, Sardinha LB, Froberg K, Ekelund U, Brage S, Anderssen SA (2006) Physical activity and clustered cardiovascular risk in children: a cross-sectional study (The European Youth Heart Study). Lancet 368(9532):299-304. https://doi.org/10.1016/ S0140-6736(06)69075-2

21. Lang RM, Badano LP, Mor-Avi V, Afilalo J, Armstrong A, Ernande L, Flachskampf FA, Foster E, Goldstein SA, Kuznetsova T, Lancellotti P, Muraru D, Picard MH, Rietzschel ER, Rudski L, Spencer KT, Tsang W, Voigt JU (2015) Recommendations for cardiac chamber quantification by echocardiography in adults: an update from the American Society of Echocardiography and the European Association of Cardiovascular Imaging. Eur Heart J Cardiovasc Imaging 16(3):233-270. https://doi.org/10.1093/ehjci/ jev014

22. Levy D, Garrison RJ, Savage DD, Kannel WB, Castelli WP (1990) Prognostic implications of echocardiographically determined left ventricular mass in the Framingham Heart Study. N Engl J Med 322(22): 1561-1566. https://doi.org/10.1056/NEJM199005313222203

23. Gerdts E, Wachtell K, Omvik P, Otterstad JE, Oikarinen L, Boman K, Dahlöf B, Devereux RB (2007) Left atrial size and risk of major cardiovascular events during antihypertensive treatment: losartan intervention for endpoint reduction in hypertension trial. Hypertension 49(2):311-316. https://doi.org/10.1161/01.HYP. 0000254322.96189 .85

24. Nagarajarao HS, Penman AD, Taylor HA, Mosley TH, Butler K, Skelton TN, Samdarshi TE, Aru G, Fox ER (2008) The predictive value of left atrial size for incident ischemic stroke and all-cause mortality in African Americans: the Atherosclerosis Risk in Communities (ARIC) Study. Stroke 39(10):2701-2706. https:// doi.org/10.1161/STROKEAHA.108.515221

25. Lundberg M, Eriksson A, Tran B, Assarsson E, Fredriksson S (2011) Homogeneous antibody-based proximity extension assays provide sensitive and specific detection of low-abundant proteins in human blood. Nucleic Acids Res 39(15):e102. https://doi.org/10. 1093/nar/gkr424

26. Assarsson E, Lundberg M, Holmquist Get al. (2014) Homogenous 96-plex PEA immunoassay exhibiting high sensitivity, specificity, and excellent scalability. PLoS One 9(4):e95192. https://doi.org/10. 1371/journal.pone.0095192

27. Uluca Ü, Șen V, Ece A, Tan İ, Karabel D, Aktar F, Karabel M, Balık H, Güneș A (2015) Serum galectin-3 levels in children with chronic hepatitis B infection and inactive hepatitis B carriers. Med Sci Monit 21:1376-1380. https://doi.org/10.12659/MSM.894035

28. Ezzat MH, El-Gammasy TM, Shaheen KY, Osman AO (2011) Elevated production of galectin-3 is correlated with juvenile idiopathic arthritis disease activity, severity, and progression. Int $\mathrm{J}$ Rheum Dis 14(4):345-352. https://doi.org/10.1111/j.1756-185X. 2011.01632.x 
29. Borges CB, Bernardes ES, Latorraca EF, Becker AP, Neder L, Chammas R, Roque-Barreira MC, Machado HR, de Oliveira RS (2011) Galectin-3 expression: a useful tool in the differential diagnosis of posterior fossa tumors in children. Childs Nerv Syst 27(2): 253-257. https://doi.org/10.1007/s00381-010-1262-3

30. Sharabiani MT, Vermeulen R, Scoccianti C et al (2011) Immunologic profile of excessive body weight. Biomarkers 16(3):243-251. https://doi.org/10.3109/1354750X.2010.547948

31. DeBoer MD (2013) Obesity, systemic inflammation, and increased risk for cardiovascular disease and diabetes among adolescents: a need for screening tools to target interventions. Nutrition 29(2): 379-386. https://doi.org/10.1016/j.nut.2012.07.003

32. Schipper HS, Nuboer R, Prop S, van den Ham HJ, de Boer FK, Kesmir Ç, Mombers IMH, van Bekkum KA, Woudstra J, Kieft JH, Hoefer IE, de Jager W, Prakken B, van Summeren M, Kalkhoven E (2012) Systemic inflammation in childhood obesity: circulating inflammatory mediators and activated CD14++ monocytes. Diabetologia 55(10):2800-2810. https://doi.org/10.1007/s00125012-2641-y

33. Reinehr T, Karges B, Meissner T, Wiegand S, Stoffel-Wagner B, Holl RW, Woelfle J (2016) Inflammatory markers in obese adolescents with type 2 diabetes and their relationship to hepatokines and adipokines. J Pediatr 173:131-135. https://doi.org/10.1016/j.jpeds. 2016.02.055

34. Kiwaki K, Novak CM, Hsu DK, Liu FT, Levine JA (2007) Galectin-3 stimulates preadipocyte proliferation and is upregulated in growing adipose tissue. Obesity (Silver Spring) 15(1):32-39. https://doi.org/10.1038/oby.2007.526

35. Krautbauer S, Eisinger K, Hader Y, Buechler C (2014) Free fatty acids and IL-6 induce adipocyte galectin-3 which is increased in white and brown adipose tissues of obese mice. Cytokine 69(2): 263-271. https://doi.org/10.1016/j.cyto.2014.06.016

36. Menini S, Iacobini C, Blasetti Fantauzzi C, Pesce CM, Pugliese G (2016) Role of galectin-3 in obesity and impaired glucose homeostasis. Oxidative Med Cell Longev 2016:9618092

37. Yancy CW, Jessup M, Bozkurt B et al (2013) 2013 ACCF/AHA Guideline for the Management of Heart Failure: a report of the American College of Cardiology Foundation/American Heart Association Task Force on Practice Guidelines. Circulation 16: e147-e239

38. Jahn LA, Hartline L, Rao N, Logan B, Kim JJ, Aylor K, Gan LM, Westergren HU, Barrett EJ (2016) Insulin enhances endothelial function throughout the arterial tree in healthy but not metabolic syndrome subjects. J Clin Endocrinol Metab 101(3):1198-1206. https://doi.org/10.1210/jc.2015-3293 